\title{
O potencial narrativo dos lugares destinados às crianças: incursões do grupo de pesquisa em psicologia da infância GPPIN ${ }^{\star}$
}

\author{
Daniela B. S. Freire Andrade $\star \star$ \\ Universidade Federal de Mato Grosso, Cuiabá, MT, Brasil
}

\begin{abstract}
Resumo
O texto discute o potencial narrativo dos espaços da infância por meio de estudos sobre significações e práticas socioeducativas destinadas às crianças na Educação Infantil. Fundamentado na Teoria Histórico Cultural, na abordagem ontogenética da Teoria das Representações Sociais em diálogo com a noção de minorias ativas (MOSCOVICI, 2011) e espaço narrativo (SENETT, 1990), procura responder se crianças são capazes de influenciar processos de significação da realidade e exercer influência social. Apresenta dois estudos que discutem o berçário como artefato cultural, cujas significações orientam profissionalidades de educadoras e regulam estruturas de oportunidade para o desenvolvimento de bebês. Revela o ser e estar de bebês mediante nova organização espacial do berçário anunciando possibilidades de aprendizagem e inserção da educadora na cena lúdica pelo bebê. As análises dos estudos revelam novas significações sobre a criança no contexto das práticas educativas e de pesquisa destacando seu poder de criação.
\end{abstract}

Palavras-chave: lugar; narrativa; educação infantil.

\section{The narrative potencial of the places destinated to children: incursions of the research group in childhood psychology RGCP}

\begin{abstract}
The text discusses the narrative potential of childhood spaces through the studies about significances and social-educational practices designated to children in Infantile Education. Based on the Cultural Historical Theory, in the ontogenetic approach of Social Representations Theory in dialogue with the notion of active minorities (MOSCOVICI, 2011) and narrative space (SENNETT, 1990) it tries to answer whether the children are capable of influencing the process of significance of the reality and perform social influence. It presents two studies that discuss the nursery as a cultural artifact, whose significances orient the professionalities of educators and regulate structures of opportunities for the development of babies. It reveals the being of babies by a new spatial organization of the nursery announcing learning possibilities and the insertion of the educator in the playful picture of the baby. The analyses of the studies reveal new significations about the child within the context of educational practices and research highlighting its power of creation.
\end{abstract}

Keywords: place; narrative; infantile education.

Sobre o Grupo de Pesquisa em Psicologia da Infância (GPPIN)

O grupo de pesquisa em Psicologia da Infância (GPPIN) define seu interesse pelos estudos sobre os processos de significações que envolvem crianças e adultos, segundo a abordagem psicossocial.

A infância é definida como construção sociocultural cujos significados regulam práticas sociais e educacionais frente às quais adultos e crianças interagem, incorporando-as, negando-as e mesmo reinterpretando-as.

Desse modo, investigam-se os processos decorrentes da relação entre a criança e seu outro, estando este presente seja no campo da intersubjetividade imediata, seja no campo da intersubjetividade anônima - o espaço como artefato cultural.

O desenvolvimento humano é compreendido segundo a abordagem histórico-cultural em diálogo com estudos na perspectiva ontogenética das representações sociais, estabelecendo, por meio das reflexões de Castorina (2010), o diálogo entre os estudos de Vigotski (2006,

\footnotetext{
^ Grupo de Pesquisa em Psicologia da Infầncia (GPPIN) coordenado pela Doutora em Educação, Docente do Programa de Pós-Graduação em Educação da Universidade Federal de Mato Grosso, campus Cuiabá, Daniela B. S. Freire Andrade

$\star \star$ Endereço para correspondência: Universidade Federal de Mato Grosso, Pró-

Reitoria de Ensino e Graduação, Instituto de Educação. Avenida Fernando

Correia, s/n - Cidade Universitária. Coxipó. CEP: 78060-900 - Cuiaba, MT

- Brasil.E-mail: freire.d@terra.com.br
}

2009, 2010) e Moscovici (2003) - teoria das representações sociais e teoria da inovação ou minorias ativas (MOSCOVICI, 2011).

Especificamente, o que se põe em questão é a dupla condição da criança ora como objeto de representação dos adultos, ora como sujeitos que elaboram novos sentidos sobre a realidade.

Os argumentos elaborados, a partir do diálogo entre os autores citados, têm revelado novos desafios no âmbito da relação estabelecida entre os estudos em representações sociais e a forte influência da abordagem histórico-cultural reconhecida como perspectiva teórica convergente aos estudos de Moscovici (2003) e Jodelet (2001, 2002).

Considerando o debate de Jodelet (2005), que aproxima a discussão do conceito de vivência, a esfera subjetiva de pertencimento das representações sociais, bem como os estudos sobre minorias ativas desenvolvido por Moscovici (2003), o GPPIN tem mobilizado esforços investigativos em torno da seguinte questão:

Serão crianças capazes de influenciar processos de significação da realidade de forma a concorrer para a construção de representações sociais e exercer influência social? 
Até o momento, os estudos têm revelado que a norma da originalidade compreendida como um dos princípios organizadores dos processos comunicacionais tem contribuído para o estabelecimento de vivências marcadas pelo respeito à alteridade e pelos laços de solidariedade, relativizando, portanto, a importância da consistência dos argumentos e de estilos de comportamentos pautados na objetividade.

O raciocínio exposto acima permite que se elabore o seguinte raciocínio: os reguladores sociais, objetivados na organização dos espaços destinados às crianças, revelam sistemas de representações que evidenciam aspectos da produção de diferentes modos de ser e estar no mundo, atuando como marcos epistêmicos que orientam as crianças na sua relação com a cultura. Nesse sentido, espaço passa a ter um valor paradigmático cujos conteúdos representacionais sustentam tanto a dimensão linear - norma da objetividade - do que se convencionou ser a infância, quanto a dimensão narrativa - norma da originalidade -, caracterizada pela participação ativa e criativa das próprias crianças.

Segundo Tuan (1983), o espaço, ao ser ordenado e significado, torna-se um lugar. Esta significação depende de vários fatores como: cultura, memória social, idade e percepções das pessoas. Desse modo, o conteúdo representacional objetivado no espaço, bem como sua interação com os usuários ativam processos afetivos que fazem do espaço um lugar emblemático atrativo ou não.

Próximo à compreensão sobre o potencial de lugar dos espaços, Sennett (1990) propõe a noção de espaço narrativo como algo próximo de uma abstração, uma vez que são espaços que narram uma ficção para fazer com que o lugar tenha um sentido, um caráter, constituindo, nessa medida, a personificação de um lugar. Portanto, "o espaço narrativo pode ser entendido como um espaço aberto para o desenvolvimento de atividades imprevisíveis de eventos, que se colocam de forma aberta para criar uma história. Essa história pode ser objeto de interpretação ou ponto de partida para outras histórias" (SENNETT, 1990, p. 190).

Nesse sentido, compreende-se que espaços significados pela norma da originalidade transformam-se com maior propriedade em lugares narrativos (SENNETT, 1990), contexto onde se estabelecem relações horizontais entre crianças e adultos em uma postura de abertura para o outro.

Diante desse panorama teórico, a expressão o potencial narrativo dos lugares da infância (ANDRADE, 2007; 2011) se apresenta como uma proposição que busca ir ao encontro da representação da criança reconhecida em seu poder de criação, pessoas que produzem cultura, além de serem nela produzidas. Coerente com esse significado, entende-se que crianças possuem narrativas próprias, veiculadas seja verbalmente, seja corporalmente, que também circulam nos espaços em busca de contornos de lugares específicos influenciando comportamentos dos adultos e de outras crianças.

Atualmente, o GPPIN tem investigado contextos em um exercício de captura de seus respectivos potenciais narrativos: a formação inicial e continuada de professo- res, a educação infantil, o ensino fundamental - turmas submetidas à Provinha Brasil -, a pediatria de um hospital universitário e a própria cidade de Cuiabá.

\section{Sobre o projeto guarda-chuva:}

O potencial narrativo dos espaços da infância: estudo das significações e das práticas socioeducativas destinadas às crianças

Trata-se de uma proposição do tipo "guarda-chuva" que objetiva compreender, por meio de vários estudos, processos de significação sobre a relação estabelecida entre infância e os espaços à ela destinados na perspectiva de adultos e de crianças.

O procedimento metodológico adotado prevê entrevistas, observações, videografia e coleta de material iconográfico. $\mathrm{O}$ material coletado tem sido analisado com auxílio de análise compreensiva e microgenética, além do exercício de identificação de núcleos de significações (AGUIAR, OZELLA, 2006), às vezes com apoio de programa computacional.

O projeto se organiza em torno de dois eixos, a saber:

- $\quad$ Eixo I - Ser e estar de crianças em espaços institucionais de educação infantil e saúde.

- $\quad$ Eixo II - Significações de professores e futuros professores sobre objetos de representações sociais em contexto da educação infantil.

\section{Considerações sobre duas pesquisas entrecruzadas no contexto da educação infantil}

Entre os anos de 2011 e 2013, o Grupo de Pesquisa em Psicologia da Infância (GPPIN) desenvolveu dois subprojetos de pesquisa, que foram delineados em torno dos resultados das atividades de extensão conhecida como Rede de Apoio à Educação Infantil: interfaces com a Psicologia, Pedagogia e Arquitetura.

O processo de reorganização espacial de um berçário da rede pública de educação de Cuiabá-MT havia sido iniciado desde 2009 por meio das ações do estágio básico em contextos socioeducativos do curso de Psicologia da Universidade Federal de Mato Grosso, que consistia em, no âmbito da formação em serviço, inserir brinquedos experimentais associados ao exercício de observação da relação dos bebês com o espaço juntamente com as profissionais que atuavam no berçário.

As intervenções que envolviam planejamento junto à equipe das profissionais que atuavam no berçário foram consideradas momentos emblemáticos e facilitadores da emergência de significados fortemente partilhados e negociados pelo grupo sobre a docência na educação infantil. Orientadores de práticas educativas, tais significados estavam sendo objetivados tanto na organização, quanto na reorganização do espaço por meio da escolha dos brinquedos, dos lugares para instalação dos mesmos bem como do delineamento dos espaços privilegiados para permanência das profissionais.

Desse modo, a abordagem investigativa do tipo etnográfica mostrou-se o recorte metodológico mais adequado. 
$\mathrm{O}$ arranjo dos estudos se deu por meio das pesquisas de Silveira (2013) - Berçário como lugar: significações segundo profissionais da Educação Infantil das unidades de atendimento à criança de até três anos no município de Cuiabá -, e de Alves (2013) - Bebês por entre vivências, afordâncias e territorialidades infantil: de como o berçário se transforma em lugar.

Com relação ao recorte metodológico, considerou-se o fato de ambos os estudos procederem à coleta de informações em duas fases - antes e depois da reorganização espacial: Situação I e Situação II.

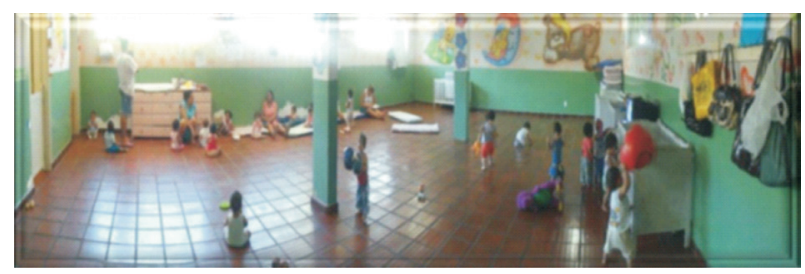

Foto 1 - Situação I do berçário em estudo. Fonte: Iury Lara. (Junho de 2012)

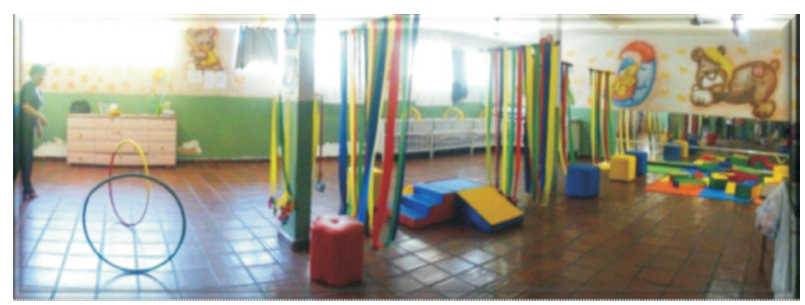

Foto 2 - Situação II do berçário em estudo. Fonte: Iury Lara. (Agosto de 2012)

As organizações espaciais configuradas na Situação I e na Situação II foram compreendidas como objetivações de representações sociais sobre educação infantil como espaço de guarda - Situação I - e como espaço educativo - Situação II.

Na primeira situação, o conteúdo da representação social emergia de práticas profissionais ancoradas na memória social que anunciavam a ênfase nos cuidados como única prioridade do serviço prestado à população. Já no segundo caso, considerou-se a interferência dos discursos referenciados no universo reificado relativos à pedagogia da educação infantil (CERISARA, 2002), que atuaram como elementos de contradição presentes no processo de formação de professores seja na graduação, na pós-graduação ou nos cursos de formação em serviço.

[...] a construção de um trabalho junto às crianças até seis anos de idade que, apesar de ser formalmente estruturado, pretende garantir a elas viver plenamente a sua infância sem imposição de práticas ritualísticas inflexíveis, tais como se cristalizam nas rotinas domésticas, escolares e hospitalares. O que se reivindica é o espaço para a vida, para a vivência dos afetos - alegrias e tristezas-, para as relações entre coetâneos e não coetâneos, para os conflitos e encontros, para a ampliação do repertório vivencial e cultural das crianças a partir de um compromisso dos adultos baseado na responsabilidade de organizar o estar das crianças em instituições educativas que lhes permitam construir sentimentos de respeito, troca, compreensão, alegria, apoio, amor, confiança, solidariedade, entre outros; enfim, que ajudem a acreditar em si mesmas e no seu direito de viver de forma digna e prazerosa (CERISARA, 2002, p. 108-109).

As diferentes representações sociais sobre educação infantil orientaram a organização dos cenários que propunham universos de socialização distintos aos bebês e suas educadoras. Por sua vez, foi possível identificar os contornos das vivências dos bebês em ambas as organizações espaciais.

Para a análise dessa realidade, o estudo de Silveira (2013) adotou como técnica de coleta de informações a observação participante e entrevistas semiestruturadas com 12 profissionais que atuavam diretamente no berçário, entre as quais sete haviam concluído o curso de Pedagogia (cinco concluíram no modelo presencial e dois, à distância, sendo que um possuía especialização em educação infantil), uma cursou Educação Física e quatro possuíam ensino médio.A faixa etária variava entre 35 e 70 anos e tempo de serviço entre seis meses a 20 anos.

A recolha das informações considerou, tanto na Situação I quanto na Situação II, um roteiro de entrevista, elaborado para reduzir a pressão normativa, e que propunha uma situação imaginária de orientação a uma profissional novata no ambiente de trabalho - o berçário. As imagens da Situação I e Situação II foram utilizadas como mediadoras da interlocução com as educadoras. As práticas observadas e as respostas às perguntas do roteiro foram, respectivamente, analisadas pela técnica de análise de conteúdo semântica (BARDIN, 1995).

Por sua vez, o estudo de Alves (2013) utilizou registro fílmico em situação de brincadeira livre, seguido de análise episódica tendo como amostra 30 bebês sendo 15 meninas e 16 meninos, entre os quais nove bebês tinham entre 16 e 28 semanas, e os demais, entre 28 e 48 semanas.

Ao todo, foram analisados 12 episódios. ${ }^{1}$ Para efeitos deste trabalho será discutido o Episódio 10, aqui denominado como Centro de atividades e a inserção do adulto na cena lúdica pela criança.

\section{Dos resultados entrecruzados dos estudos}

As observações referentes à Situação I revelaram que a forma como o espaço e a rotina eram organizados mostram que as representações das profissionais sobre o trabalho com bebês na educação infantil ancoram-se fortemente em significados vinculados prioritariamente ao cuidado, anunciando o berçário como espaço de guarda e a profissional como espécie de mãe substituta. Tais elementos coincidem com o estudo de Ramos (2012) que, ao analisar as representações sociais de acadêmicos de Pedagogia da Universidade Federal de Mato Grosso, campus Cuiabá, sobre "ser professora de bebês", identificou que a mesma apresenta-se difusa em meio a três imagens: 1) "mãe substituta", 2) “professora", e 3) "babá”, evidenciando maior adesão à primeira e à terceira do que à segunda.

${ }^{1}$ Por episódio entendeu-se ser uma configuração interacional recortada (PEDROSA; CARVALHO, 2005). Os episódios foram selecionados conforme o desfecho da cena apresentada pelos bebês, bem como foi considerada a qualidade da adesão e engajamento na atividade, seja isolado ou partilhado entre os parceiros que a compunham. 
Após a reorganização do berçário, a movimentação dos bebês e profissionais sofreu algumas alterações. Se na Situação I havia a emergência de maior trocas entre bebês, na Situação II as trocas diminuíram a favor da exploração individual dos brinquedos agora disponíveis em número suficiente. Destaca-se que os bebês começaram a vivenciar a possibilidade de escolha do brinquedo, aspecto negado na Situação I pela precariedade ou mesmo inexistência desses objetos.

Inicialmente, as profissionais do berçário passaram a se inserir nas brincadeiras dos bebês, encorajando-os. Porém, um mês após a reorganização do espaço, observou-se o recuo dessa prática, dando lugar às práticas anteriores.

Notas do estudo 1 - no âmbito dos discursos das profissionais

Em síntese, o estudo 1 propiciou a identificação de associações que tencionam a construção da profissionalidade no trabalho com bebês em contextos de educação infantil. São elas:

1. Rotina: cuidado e integridade física são pressupostos identitários das profissionais que assumem práticas objetivadas na imagem de babá;

2. Práticas pedagógicas: vivências envolvendo bebê-espaço-profissional revelam novos significados ainda pouco familiarizados. Estes delineiam situações que equilibram aventura e segurança propiciadas pela mediação do adulto e atividade dos bebês. Essa possibilidade, que se identifica ainda em processo inicial, é objetivada nas imagens de educadora e professora.

A título de hipótese, entende-se que, ainda que apareçam timidamente no discurso, significados atribuídos ao binômio cuidar e educar, sobretudo nos discursos associados à Situação II, estão pouco traduzidos na concretude das práticas desenvolvidas no berçário.

Nesse sentido, o estudo 2 contribui para a evidência de processos que anunciam a construção do novo, considerando as vivências envolvendo bebê-espaço-profissional do berçário.

\section{Notas do segundo estudo: mais próximo da perspectiva do bebê ou de como nasce o entendimento sobre o binômio cuidar e educar}

Episódio 10 - Centro de atividades e a inserção do adulto na cena lúdica pela criança.

Descrição 1: nota de campo 29/8/2011.

A bebê Lud estava no chão, próxima ao centro de atividades, ela observava uma berçarista. Esta auxiliava o bebê En a subir no centro de atividades. A bebê Lud permaneceu um bom tempo observando, até que a berçarista saiu do centro de atividades.

Nesse instante, a bebê Lud continuou a observar os movimentos dos bebês En e Ing. Logo, os bebês se dispersaram, e a bebê Lud ficou sozinha próxima ao centro de atividades. Por vezes, ela ensaiou a possibilidade de subir, mas logo desistiu.

Passado algum tempo, a bebê Lud continuou a observar o centro de atividades; alguns bebês se aproximam e logo saíam daquele local. Houve um momento em que uma berçarista percebeu a bebê Lud e seus movimentos de ensaio para subir, no entanto, sem completar a rampa do centro. Nesse instante, a berçarista se posicionou diante da bebê Lud e, com um sorriso, a encorajou a subir. Lud se movimentou em direção à berçarista e fez o trajeto de subir e descer a rampa do centro de atividades.

Não obstante as informações do primeiro estudo evidenciarem a forte tendência das práticas educacionais do berçário ancoradas na representação da educação infantil como espaço de guarda, com ênfase nas atividades de cuidado, o episódio acima descrito revela vivência caracterizada pela negociação de sentidos entre o profissional e o bebê, na medida em que o bebê Lud anunciou, por meio de uma sequência de movimentos e olhares, uma necessidade premente de apoio, encorajamento e segurança.

A unidade "bebê-espaço reorganizado-profissional do berçário" configurou um cenário no qual vivências se complementaram na direção das ações educativas aparentemente negadas pela própria equipe de profissionais. Desse modo, pode-se perceber a emergência, no âmbito da prática, do significado atribuído ao binômio cuidar e educar, vivenciado na sua integralidade fazendo, emergir um episódio no qual, complementarmente, o bebê explora o espaço com aventura e com segurança e a profissional assume a faceta identitária que lhe confere o papel social de tutora privilegiada na cena educativa.

Nesse cenário, evidencia-se outra rede de significados ancorada nos pressupostos da pedagogia da educação infantil (CERISARA, 2002), ao mesmo tempo que destaca a importância da ludicidade como atividade-guia (PRESTES, 2011), geradora de neoformações no desenvolvimento psicológico da criança.

\section{Considerações}

Ao tecer as considerações deste texto, destacam-se quatro categorias interpretativas: 1) o espaço como elemento de mediação do diálogo entre pesquisadores e profissionais da educação infantil no exercício de construção da transparência do discurso; 2) a dupla condição do espaço tomado ora como objetivação de representações sociais, ora como objeto de representação; 3) a manifestação das funções identitárias e de resistência na relação com as representações sociais sobre o berçário; 4) a possibilidade de transformação das representações sociais revelada por meio da vivência estabelecida entre os bebês, o espaço e as profissionais do berçário.

Com relação à primeira categoria, observou-se que o diálogo em torno do berçário se constituiu como um exercício que revelava, em um primeiro momento, a responsabilidade das políticas públicas pela cena instaurada, sobretudo com relação à Situação I. Acredita-se que este aspecto tenha contribuído para a diminuição da pressão normativa, justificando as referências relativas às práticas educativas adotadas. Já no aspecto que considerou o espaço como objetivação e objeto de representação social, destaca-se que, ao analisarem as fotos referentes às Situações I e II , as profissionais acessaram prontamente significados sobre o trabalho na educação infantil 
diferentes, embora a adesão estivesse direcionada aos significados mais rotinizados que associam a educação infantil ao sentido de guarda. Tal fato revela que o registro imagético das diferentes organizações espaciais pode ser considerado como indutor de significações úteis ao estudo das famílias de representações sociais.

Ainda com relação aos discursos decorrentes das diferentes organizações espaciais, destaca-se a evidência de que, ao falarem do espaço as profissionais também evidenciaram a dimensão identitária das representações sociais - valorização do profissional, melhor condição de trabalho e a ancoragem nos significados associados a babá e a profissional. Sobre esse aspecto, foi possível observar movimentos característicos daquilo que Bauer (1994) anunciou como função de resistência das representações sociais.

Alguns elementos podem ser considerados no sentido de compreender a necessidade de resistir às mudanças, tais como: o entendimento de que as mudanças sugeridas fossem imposições - embora a adesão da instituição ao projeto tenha se orientado pelo desejo da equipe -, a presença de profissionais com diferentes perfis considerando formação, tempo de serviço e vínculo com a profissão, bem como a existência de entendimentos divergentes com relação à necessidade de mudança da abordagem educacional.

Assim, pode-se dizer que o espaço reorganizado do berçário objetivou dois paradigmas orientadores da educação infantil aspecto que suscitou um novo processo de negociação de significados no interior do grupo de pertencimento.

O fato da ideia de mudança da organização espacial do berçário ter sido apresentada como uma escolha e não como uma imposição à equipe pode ter contribuído para a emergência de uma adesão mais periférica às novas práticas instauradas, que, paulatinamente, perderam as forças frente à rotinização das práticas anteriores.

No entanto, as oportunidades de exploração do espaço que emergem nas vivências infantis, observadas a partir da perspectiva ontogenética das representações sociais, evidenciam outro tipo de cenário favorável às transformações das práticas e das representações sociais. Sem contestar, o pressuposto da segurança física do bebê como principal organizador das representações sociais sobre o trabalho na educação infantil e orientador das práticas das profissionais do berçário, a vivência em torno da unidade bebê-brinquedo desafia o adulto a se colocar como aquele que apoia a ação do bebê ao mesmo tempo em que procura anular os potenciais perigos daquela atividade. Nessa prática, mobilizada pela atenção ao cuidado, emerge o sentido, ainda que ao nível intuitivo, proposto pelo binômio cuidar-educar.

\section{Referências}

AGUIAR, W. M. J.; OZELLA, S. Núcleos de significação como instrumento para a apreensão da constituição dos sentidos. Psicol. Cienc. Prof., Brasília, v. 26, n. 2, p. 222-245, jun. 2006.

ANDRADE, D.B.S.F. O lugar feminino na escola: um estudo em representações sociais. Cuiabá: EdUFMT, 2007.

ANDRADE, D.B.S.F. O potencial narrativo dos espaços da infância: estudo das significações e das práticas socioeducativas destinadas às crianças. Projeto de Pesquisa. Cuiabá, FAPEMAT, 2011.

ALVES, I. L. Bebês por entre vivências, afordâncias $e$ territorialidades infantil: de como o berçário se transforma em lugar. 2013. Dissertação (Mestrado em Educação)-Programa de Pós-Graduação em Educação, Universidade Federal de Mato Grosso, Cuiabá, 2013.

BARDIN, L. Análise de conteúdo. Tradução de Luís Antero Reto e Augusto Pinheiro. Lisboa: Edições 70, 1995.

BAUER, M. A popularização da ciência como iluminação cultural: a função de resistência das representações sociais. In: GUARECHI, P. A.; JOVCHELOVITCH, S. Textos em Representações sociais. Petrópolis, RJ: Vozes, 1994. p. 229261.

CASTORINA, J. A. The ontogenesis of social representations: a dialetic perpective. Papers on social representation, [S.1.], v. 19, n. 1, p. 18.1-18.19, 2010. Disponível em: <http://www. psych.1se.ac.uk/psr/>. Acesso em: 28 abr. 2013.

CERISARA, B. Professoras de Educação Infantil: entre o feminino e o profissional. São Paulo: Cortez, 2002.

JODELET, D. (Org.). Representações sociais: um domínio em expansão. In: . As representações sociais. Tradução de Lílian Ulup. Rio de Janeiro: EdUERJ, 2001. p. 17-44.

JODELET, D. A cidade e a memória. In: DEL RIO, V.; DUARTE, C. R.; RHEInGANTZ, P. A. (Org.). Projeto de Lugar: colaboração entre psicologia, arquitetura e urbanismo. Rio de Janeiro: Contra Capa, 2002. Coleção ProArquitetura, p.31-43.

JODELET, D. Experiência e representações sociais. São Paulo: Casa do Psicólogo, 2005.

MOSCOVICI, S. Representações Sociais:investigações em Psicologia Social. Tradução de Pedrinho A. Guareschi. Petrópolis, RJ: Vozes, 2003.

MOSCOVICI, S. Psicologia das minorias ativas. Tradução de Pedrinho A. Guareschi - Grupo de Leitura Ideologia, Comunicação e Representações Sociais. Petrópolis, RJ: Vozes. 2011.

PEDROSA, M. I.; CARVALHO, A. M. A.. Análise qualitativa de episódios de interação: uma reflexão sobre procedimentos e formas de uso. Psicologia Reflexão e Crítica, Porto Alegre, v. 18, n. 3, p. 431-442, 2005.

PRESTES, Z. R. A brincadeira de faz-de-conta como atividadeguia. In: CONGRESSO DE EDUCAÇÃO BÁSICA, 2011. Florianópolis: COEB, 2011. v. 1. Disponível em: $<$ http://portal. pmf.sc.gov.br/arquivos/arquivos/ pdf/>. Acesso em: 28 nov. 2011

SENNETT, R. The conscience of the eye:the design and social life of cities. New York: Norton \& Company, 1990.

SILVEIRA, G. L. Berçário como lugar: significações segundo profissionais da Educação Infantil das unidades de atendimento à criança de até três anos no município de Cuiabá. 2013. Dissertação (Mestrado em Educação)- Programa de PósGraduação em Educação, Universidade Federal de Mato Grosso, Cuiabá, 2013.

RAMOS, C. A. R. De mãe substituta a babá malvada? Representações sociais sobre professora de bebês segundo acadêmicos de pedagogia da UFMT, campus Cuiabá. 2012. Dissertação (Mestrado) Programa de Pós Graduação em Educação, Universidade Federal de Mato Grosso, 2012. 
Disponível em: <http://www.ie.ufmt.br/ppge/dissertacoes/ index.php>. Acesso em: 22 jul. 2013.

TUAN, Y.-F. Espaço e lugar: a perspectiva da experiência. São Paulo: Difel, 1983.

VIGOTSKI, L. S. A crise dos sete anos. Traduzido de: VIGOTSKI, L. S. La crisis de lós siete años. Obras escogidas. Tomo IV. Madrid: Visor y A. Machado, 2006. p.377-386.

VIGOTSKI, L. S. Imaginação e criação na infância: ensaio psicológico: livro para professores. Apresentação e comentários de Ana Luiza Smolka. Tradução de Zoia Ribeiro Prestes. São Paulo: Ática, 2009.

VIGOTSKI, L. S. Quarta aula: a questão do meio na pedologia. Psicologia USP, São Paulo, v. 21, n. 4, p. 681-701, 2010. Tradução de Márcia Pilleggi Vinha.

Recebido em: 29 de agosto de 2013

Aceito em: 03 de setembro de 2014 